\title{
Discrepancy Between Clinical and Pathologic Nodal Status of Esophageal Cancer and Impact on Prognosis and Therapeutic Strategy
}

\author{
Sheraz R. Markar, $\mathrm{PhD}^{1}$, Caroline Gronnier, $\mathrm{PhD}^{2,3,4}$, Arnaud Pasquer, $\mathrm{MD}^{5}$, Alain Duhamel, $\mathrm{PhD}^{6,7}$, \\ Hélène Behal, $\mathrm{PhD}^{6,7}$, Jérémie Théreaux, $\mathrm{MD}^{8}$, Johan Gagnière, $\mathrm{MD}^{9}$, Gil Lebreton, $\mathrm{MD}^{10}$, Cécile Brigand, $\mathrm{MD}^{11}$, \\ Florence Renaud, $\mathrm{MD}^{3,4,12}$, Guillaume Piessen, $\mathrm{PhD}^{2,3,4}$, Bernard Meunier, $\mathrm{MD}^{13}$, Denis Collet, $\mathbf{M D}^{14}$, \\ Christophe Mariette, MD, PhD ${ }^{2,3,4,6,15}$, and on Behalf of the FREGAT Working Group-FRENCH-AFC \\ ${ }^{1}$ Department of Surgery and Cancer, Imperial College, London, UK; ${ }^{2}$ Department of Digestive and Oncological Surgery, \\ Univ.Lille, Claude Huriez University Hospital, Lille, France; ${ }^{3}$ Univ.Lille, UMR-S 1172 - JPARC - Centre de Recherche \\ Jean-Pierre AUBERT Neurosciences et Cancer, Lille, France; ${ }^{4}$ Inserm, UMR-S 1172, Lille, France; ${ }^{5}$ Department of \\ Digestive Surgery of Edouard, Herriot University Hospital, Lyon, France; ${ }^{6}$ SIRIC OncoLille, Lille, France; ${ }^{7}$ Department of \\ Biostatistics, Univ.Lille, University Hospital, Lille, France; ${ }^{8}$ Cavale Blanche University Hospital, Brest, France; ${ }^{9}$ Estaing \\ University Hospital, Clermont-Ferrand, France; ${ }^{10}$ Côte de Nacre University Hospital, Caen, France; ${ }^{11}$ Hautepierre \\ University Hospital, Strasbourg, France; ${ }^{12}$ Department of Pathology, Univ.Lille, University Hospital, Lille, France; \\ ${ }^{13}$ France Pontchaillou University Hospital, Rennes, France; ${ }^{14}$ Haut-Levêque University Hospital, Bordeaux, France; \\ ${ }^{15}$ Department of Digestive and Oncological Surgery, University Hospital Claude Huriez-Regional University Hospital \\ Center, Lille Cedex, France
}

\begin{abstract}
Background. The impact of discrepancies between clinical (c) and pathologic (p) stages of esophageal cancer remains a poorly understood issue. This study aimed to compare the prognosis of patient groups treated by primary surgery including clinical N0/pathologic NO (cNOpNO), clinical N0/pathologic $\mathrm{N}+(\mathrm{cNOpN}+)$, clinical $\mathrm{N}+$ /patho$\operatorname{logic} \mathrm{N} 0(\mathrm{cN}+\mathrm{pN} 0)$, and clinical $\mathrm{N}+$ /pathologic $\mathrm{N}+$ $(\mathrm{cN}+\mathrm{pN}+)$.

Methods. Data were collected from 30 European centers during the years 2000 to 2010. Among 2944 recruited patients, 1554 patients receiving primary surgery met the inclusion criteria including $613 \mathrm{cN} 0 \mathrm{pN} 0,403 \mathrm{cN} 0 \mathrm{pN}+$, $220 \mathrm{cN}+\mathrm{pN}$, and $318 \mathrm{cN}+\mathrm{pN}+$ patients. Analyses with
\end{abstract}

Collaborators are listed in Appendix 2.

(C) The Author(s) 2017. This article is an open access publication

First Received: 2 July 2017;

Published Online: 25 September 2017

C. Mariette, $\mathrm{MD}, \mathrm{PhD}$

e-mail: christophe.mariette@chru-lille.fr adjustment of the propensity score were used to compensate for differences in baseline characteristics.

Results. Clinical $\mathrm{T}$ stages 3 and 4 were increased in $\mathrm{cN}+\mathrm{pN}+(73.0 \%), \quad \mathrm{cN} 0 \mathrm{pN}+(49.6 \%), \quad$ and $\mathrm{cN}+\mathrm{pN} 0$ (51.8\%) compared with cNOpNO (32.8\%). Compared with $\mathrm{cN} 0 \mathrm{pNO}, \mathrm{cN}+\mathrm{pN}+$ and $\mathrm{cNO} 0 \mathrm{pN}+$ showed an increase in the proportion of adenocarcinoma histologic subtype, poor tumor differentiation, pathologic T3 and T4 stages, and R1/ 2 resection margin. Adjusted 5-year overall survival (hazard ratio [HR] 3.12; 95\% confidence interval [CI] 2.57-3.78; $P<0.001$ ) and event-free survival (HR 2.87; $95 \%$ CI $2.39-3.45 ; P<0.001)$ were significantly reduced in $\mathrm{cN} 0 \mathrm{pN}+$ compared with $\mathrm{cN} 0 \mathrm{pNO}$. No significant differences in 5-year overall survival or event-free survival between $\mathrm{cNO} 0 \mathrm{pN}+$ and $\mathrm{cN}+\mathrm{pN}+$ were observed. Regression analysis identified an association of distal tumor location, advanced clinical $\mathrm{T}$ stage, and poor tumor differentiation with $\mathrm{pN}+$ disease.

Conclusions. This large multicenter study showed that $\mathrm{cN} 0 \mathrm{pN}+$ has a prognosis similar to that of $\mathrm{cN}+\mathrm{pN}+$ and worse than that of cNOpNO. Patients with clinical NO disease but risk factors for pathologic $\mathrm{N}+$ disease may benefit from neoadjuvant therapy before surgery. 
In recent years, the treatment methods available for esophageal cancer have increased substantially. ${ }^{1-3}$ Paralleling this growth in treatment options has been a growth in evidence for patient- and tumor-specific strategies. ${ }^{4-6}$ However current guidelines are limited by the quality of the available evidence for individual clinical stages and histologic subtypes of esophageal cancer, which often are grouped together in publications to increase the statistical power of the study at the cost of creating heterogeneous analyses. Consequently, ensuring interpretation of results remains challenging. $^{7-9}$

Treatment of clinical N0/pathologic $\mathrm{N}+(\mathrm{cNOpN}+)$ esophageal cancer remains a relatively controversial and poorly understand issue. Adjuvant therapy for patients with $\mathrm{pN}+$ esophageal cancer has limited efficacy in improving long-term prognosis. ${ }^{10}$ Therefore, many clinicians have advocated for the use of neoadjuvant therapy in the treatment of patients with cT2/3 N0 esophageal cancer due to the $20 \%$ of $\mathrm{pN}+$ disease in esophageal cancers with submucosal invasion. ${ }^{11,12}$ However, it may be perceived that this is a highly aggressive and unnecessary treatment approach because the prognosis for $\mathrm{cNO} \mathrm{pN}+$ has previously not been compared with clinical $\mathrm{N}+$ /pathologic $\mathrm{N}+(\mathrm{cN}+\mathrm{pN}+)$ or clinical N0/pathologic $\mathrm{N} 0(\mathrm{cNOpNO})$. Therefore, it may be suggested that $\mathrm{cNOpN}+$ has an intermediate prognosis between these other two groups and therefore deserves individual consideration.

The primary objective of the current study was to compare the long-term prognosis for $\mathrm{cN} 0 \mathrm{pN}+$ patient groups treated by primary surgery with $\mathrm{cN} 0 \mathrm{pNO}$, clinical $\mathrm{N}+$ /pathological $\mathrm{N} 0(\mathrm{cN}+\mathrm{pN} 0)$, and $\mathrm{cN}+\mathrm{pN}+$ patient groups.

The secondary objectives were to compare the long-term prognosis of $\mathrm{cN} 0 \mathrm{pN}+$ patients in subset comparisons for histologic subtype and $\mathrm{T}$ stage, to evaluate the prognostic effect of adjuvant therapy in $\mathrm{cNO} 0 \mathrm{pN}+$ patients, and to identify risk factors for $\mathrm{pN}+$ status in $\mathrm{cN} 0$ patients.

\section{METHODS}

\section{Patient Eligibility Criteria}

A dedicated website (http://www.chirurgie-viscerale. org), was used to capture data from 2944 consecutive adult patients undergoing surgical resection for esophageal cancer (including Siewert types 1 and 2 junctional tumors) with curative intent in 30 French-speaking European centers between 2000 and 2010. An independent team monitored and audited the data capture to minimize missing data and to ensure both concordance and inclusion of consecutive patients.
Patient malnutrition was defined by weight loss of more than $10 \%$ during a 6-month period before surgery. Highvolume centers were defined as those performing more than eight resections per year during the 10 -year study period. $^{13}$

As recommended by French national guidelines, ${ }^{14}$ the approach to clinical staging used a combination of endoscopic ultrasound (EUS) for transversable tumors, computerized tomography (CT), and, on demand, positron emission tomography (PET). The study was accepted by the regional institutional review board on 15 July 2013, and the database was registered in the Clinicaltrials.gov website under the identifier NCT 01927016.

\section{Data Collection}

Patient demographics and tumor-related data were collected. Complications were defined on the basis of the definitions used in the MIRO trial protocol. ${ }^{15}$ Histologic staging of tumors was based on the 7th edition of the Union Internationale Contre le Cancer (UICC)/TNM classification. ${ }^{16}$

\section{Inclusion Criteria}

From the 2944 consecutive surgically treated patients collected in the database, we excluded those treated with neoadjuvant therapy $(n=1358)$ and those with metastatic disease $(n=18)$ or synchronous cancer at diagnosis ( $n=14)$, leaving 1554 patients. The treatment approach for individual patients was decided at the local center with multidisciplinary team meetings for all the participating centers.

\section{Follow-Up Evaluation: Survival and Recurrence}

During follow-up period, clinical examination and thoracoabdominal CT every 6 months for 5 years was recommended, with upper gastrointestinal endoscopy at 2 years. ${ }^{14}$ In cases of suspected recurrence, thoracoabdominal CT scan and upper gastrointestinal endoscopy were performed. Histologic, cytologic, or unequivocal radiologic proof was required before a diagnosis of recurrence was determined, and using this, disease-free survival was calculated.

\section{Statistical Analysis}

Statistical analysis was performed using SPSS version 20.0 software (SPSS, Chicago, IL, USA) or the SAS software package, release 9.3 (SAS Institute, Cary, NC, USA). Data are presented as number (\%) or median (range). 
Comparison of patient demographics, surgical technique, tumor pathology, and postoperative outcomes between the four study groups was performed using the KruskallWallis test for quantitative variables or the Chi square test (Fisher's exact test was used when expected cell frequencies were lower than 5) for categorical variables.

Overall and disease-free survivals were estimated using the Kaplan-Meier method and compared between the four study groups using the log-rank test. We further compared the overall and disease-free survivals between $\mathrm{cNO} 0 \mathrm{pN}+$ and each of the other subgroups using Cox's proportional hazard model, and hazard ratios for $\mathrm{cN} 0 / \mathrm{pN}+$ relative to each of the other subgroups were calculated as effect sizes. Proportional hazard assumption was checked using the Schoenfeld residuals.

To reduce the effects of potential confounding factors [study period, age, gender, American Society of Anesthesiologists (ASA) score, malnutrition, center volume, clinical T stage, tumor location, surgical technique, histologic subtype, adjuvant therapy] in the analysis of the short- and long-term outcomes between $\mathrm{cN} 0 / \mathrm{pN}+$ and $\mathrm{cN} 0 / \mathrm{pNO}$, and between $\mathrm{cN} 0 / \mathrm{pN}+$ and $\mathrm{cN}+/ \mathrm{pN}+$, we calculated a propensity score for each comparison. The propensity scores were estimated using a multivariable logistic regression model, with study groups as the dependent variable and potential confounding factors as the independent variables.

To avoid case deletion in propensity score adjustment analyses due to missing information for malnutrition (22\%), missing values for malnutrition were imputed by multiple imputations using all variables included in propensity score calculations (including the study groups). ${ }^{17}$ Missing data were imputed under a missing-at-random assumption by using a regression-switching approach (chained equation with $m=10$ imputations obtained using the R Statistical Software, version 3.03 (R Development Core Team, Auckland, New Zealand), with a predictive mean matching method for continuous variables, a logistic regression model for binary variables, and an ordinal logistic regression model for ordinal categorical variables. ${ }^{18}$

In each imputed data set, propensity score-adjusted analyses were performed using logistic regression models for short-term outcomes and Cox's proportional hazard models for long-term outcomes. Logistic and Cox's regressions estimates obtained in the different imputed data sets were combined using Rubin's rules. ${ }^{19}$ Adjusted odds ratios (ORs) and hazard ratios (HRs) with $95 \%$ confidence intervals (CIs) were derived from these combined estimates as effect size measurements (using $\mathrm{cN} 0 / \mathrm{pNO}$ and $\mathrm{cN}+/$ $\mathrm{pN}+$ as reference groups).

Exploratory analyses evaluating survival according to the histologic subtype and clinical $\mathrm{T}$ stage and the impact of adjuvant treatment in $\mathrm{pN}+$ groups were performed. Finally, among the cN0 patients, we studied the factors associated with $\mathrm{pN}+$ disease in bivariate and multivariate analyses. Variables associated with $\mathrm{pN}+$ disease in bivariate analyses $(P<0.05)$ were introduced into a multivariable logistic regression model.

All statistical tests were two-sided, with the threshold of significance set at a $P$ value lower than 0.05 .

\section{RESULTS}

\section{Overall Population Characteristics}

From the original data set of 2944 patients, 1610 patients did not meet the inclusion criteria (reasons described in the Methods section), leaving 1554 patients who received primary surgery and were included in this study. Clinical tumoral staging was based on CT scan for $100 \%$ of the patients, combined with endoscopic ultrasound for $73 \%$ of the patients (not transversable tumor for $15 \%$, not performed for $12 \%$ ) and PET scan for $47 \%$ of the patients. The majority of the patients were 60 years of age or older (55\%), had an ASA grade of $2(57.7 \%)$, and had undergone surgery in a high-volume center $(61.0 \%)$.

Squamous cell carcinoma was diagnosed for 719 patients $(46.3 \%)$ and adenocarcinoma for 835 patients $(53.7 \%)$. The median number of lymph nodes harvested was 16 (range 3-72), and the incidence of a $\mathrm{R} 1 / 2$ resection margin was $11.4 \%(n=177)$. The four patient groups treated by primary surgery and included in the study were cN0pNO $\quad(n=613), \quad \mathrm{cN} 0 \mathrm{pN}+\quad(n=403), \quad \mathrm{cN}+\mathrm{pN} 0$ $(n=220)$, and $\mathrm{cN}+\mathrm{pN}+(n=318)$.

\section{Comparison of Patient Demographics, Clinical and Pathologic Staging, and Outcomes Between Groups}

The groups did not differ significantly in terms of baseline patient demographics, except for the proportion of malnutrition, which was increased in the $\mathrm{cN}+\mathrm{pN}+$ group $(21.4 \%)$, the $\mathrm{cN} 0 \mathrm{pN}+$ group $(19.1 \%)$, and the $\mathrm{cN}+\mathrm{pN} 0$ group $(13.6 \%)$ compared with the cN0pN0 group (7.3\%) (Table 1). The incidence of clinical $\mathrm{T}$ stage 3 or 4 was increased in the $\mathrm{cN}+\mathrm{pN}+\operatorname{group}(73 \%)$, the $\mathrm{cN} 0 \mathrm{pN}+\operatorname{group}(49.6 \%)$, and the $\mathrm{cN}+\mathrm{pN} 0$ group $(51.8 \%)$ compared with the $\mathrm{cN} 0 \mathrm{pN} 0$ group (32.8\%). The $\mathrm{cN}+\mathrm{pN}+$ and $\mathrm{cN} 0 \mathrm{pN}+$ groups had a significantly greater proportion of lower third esophageal tumors than the $\mathrm{cN} 0 \mathrm{pNO}$ and $\mathrm{cN}+\mathrm{pN} 0$ groups. This was reflected in differing surgical techniques and increased use of the Ivor Lewis technique in the $\mathrm{cN}+\mathrm{pN}+$ and $\mathrm{cN} 0 \mathrm{pN}+$ groups. 
TABLE 1 Comparison of patient demographics and surgical technique according to clinical $(\mathrm{cN}) /$ pathologic (pN) node groups

\begin{tabular}{|c|c|c|c|c|c|c|}
\hline Variable & $\begin{array}{l}\text { Overall incidence }(n= \\
1554) n(\%)\end{array}$ & $\begin{array}{l}\text { cN0pN0 }(n=613) \\
n(\%)\end{array}$ & $\begin{array}{l}\mathrm{cN} 0 \mathrm{pN}+(n=403) \\
n(\%)\end{array}$ & $\begin{array}{l}\mathrm{cN}+\mathrm{pN} 0(n=220) \\
n(\%)\end{array}$ & $\begin{array}{l}\mathrm{cN}+\mathrm{pN}+(n=318) \\
n(\%)\end{array}$ & $P$ value \\
\hline Surgery after $2006^{\mathrm{a}}$ & $614(39.5)$ & $269(43.9)$ & $143(35.5)$ & $101(45.9)$ & $101(31.8)$ & $<0.001$ \\
\hline Age $\geq 60$ years $^{\mathrm{a}}$ & $855(55.0)$ & $330(53.8)$ & $218(54.1)$ & $137(62.3)$ & $170(53.5)$ & 0.140 \\
\hline Male incidence $^{\mathrm{a}}$ & $1256(80.8)$ & $484(79.0)$ & $330(81.9)$ & $171(77.7)$ & $271(85.2)$ & 0.072 \\
\hline \multicolumn{6}{|l|}{ ASA score ${ }^{a}$} & 0.915 \\
\hline 1 & $240(15.4)$ & $99(16.2)$ & $60(14.9)$ & $32(14.5)$ & $49(15.4)$ & \\
\hline 2 & 897 (57.7) & $360(58.7)$ & $235(58.3)$ & $126(57.3)$ & $176(55.3)$ & \\
\hline 3 & $398(25.6)$ & $147(24.0)$ & $101(25.1)$ & $60(27.3)$ & $90(28.3)$ & \\
\hline 4 & $19(1.2)$ & $7(1.1)$ & $7(1.7)$ & $2(0.9)$ & $3(0.9)$ & \\
\hline Malnutrition $^{\mathrm{a}}$ & $220(14.2)$ & $45(7.3)$ & $77(19.1)$ & $30(13.6)$ & $68(21.4)$ & $<0.001$ \\
\hline 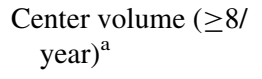 & $948(61.0)$ & $371(60.5)$ & $251(62.3)$ & $129(58.6)$ & 197 (61.9) & 0.705 \\
\hline \multicolumn{6}{|l|}{ Clinical $\mathrm{T}$ category ${ }^{\mathrm{a}}$} & $<0.001$ \\
\hline 1 & $389(25.0)$ & $265(43.2)$ & $68(16.9)$ & $44(20.0)$ & $12(3.8)$ & \\
\hline 2 & $418(26.9)$ & $147(24.0)$ & $135(33.5)$ & $62(28.2)$ & $74(23.3)$ & \\
\hline 3 & $382(24.6)$ & $68(11.1)$ & $121(30.0)$ & $55(25.0)$ & $138(43.4)$ & \\
\hline 4 & $365(23.5)$ & $133(21.7)$ & 79 (19.6) & $59(26.8)$ & $94(29.6)$ & \\
\hline \multicolumn{6}{|c|}{ Esophageal tumor location ${ }^{a}$} & $<0.001$ \\
\hline Upper & $224(14.4)$ & $112(18.3)$ & $34(8.4)$ & $48(21.8)$ & $30(9.4)$ & \\
\hline Middle & $509(32.8)$ & $227(37.0)$ & $124(30.8)$ & $74(33.6)$ & $84(26.4)$ & \\
\hline Lower & $821(52.8)$ & $274(44.7)$ & $245(60.8)$ & $98(44.5)$ & $204(64.2)$ & \\
\hline \multicolumn{6}{|l|}{ Surgical technique $^{\mathrm{a}}$} & 0.010 \\
\hline Ivor Lewis & $1098(70.7)$ & $413(67.4)$ & $310(76.9)$ & $148(67.3)$ & $227(71.4)$ & \\
\hline 3 stage & $161(10.4)$ & $67(10.9)$ & $29(7.2)$ & $33(15)$ & $32(10.1)$ & \\
\hline Transhiatal & $295(19.0)$ & $133(21.7)$ & $64(15.9)$ & $39(17.7)$ & $59(18.6)$ & \\
\hline
\end{tabular}

ASA American society of anesthesiologists

${ }^{a}$ Included in the propensity-matched analysis

Tumor pathology differed substantially between the groups (Table 2). Compared with the cNOpNO and $\mathrm{cN}+\mathrm{pN} 0$ groups, the $\mathrm{cN}+\mathrm{pN}+$ and $\mathrm{cNO} \mathrm{pN}+$ groups showed an increase in the proportion of adenocarcinoma histologic subtype, poor tumor differentiation, pathologic $\mathrm{T} 3$ or $\mathrm{T} 4$ stage, pathologic stage 3 disease, and R1/2 resection margin. The number of lymph nodes harvested was marginally greater for $\mathrm{cN}+\mathrm{pN}+(n=20$; range 3-72), $\mathrm{cN} 0 \mathrm{pN}+(n=17$; range $3-49)$, and $\mathrm{cN}+\mathrm{pNO}(n=16$; range 3-48) than for $\mathrm{cN} 0 \mathrm{pNO}(n=13$; range $3-70)$. The median number of positive lymph nodes was 3 for the $\mathrm{cN}+\mathrm{pN}+$ group and 2 for the $\mathrm{cN} 0 \mathrm{pN}+$ group. The groups did not differ significantly in short-term mortality or morbidity (Table 2).

\section{Unadjusted Long-Term Analysis}

The unadjusted 5-year overall survival (23.3\% vs $67.0 \%$; HR 3.15; 95\% CI 2.62-3.79; $P<0.001)$ and the event-free survival (20.7\% vs 61.6\%; HR 2.91; 95\% CI $2.44-3.47 ; P<0.001)$ were significantly reduced in the $\mathrm{cN} 0 \mathrm{pN}+$ group compared with the $\mathrm{cN} 0 \mathrm{pNO}$ group. Also, the findings showed significant increases in overall recurrence $(64.6 \%$ vs $19.0 \%$; HR 5.16; 95\% CI 3.94-6.75; $P<0.001)$, locoregional recurrence $(24.9 \%$ vs $9.9 \%$; HR $3.00 ; 95 \%$ CI $1.98-4.55 ; P<0.001)$, distant recurrence (28.6\% vs $6.1 \%$; HR 5.64; 95\% CI 3.52-9.05; $P<0.001$ ), and mixed recurrence $(20.1 \%$ vs $3.5 \%$; HR 5.95 ; $95 \%$ CI $3.37-10.50 ; P<0.001)$ in the $\mathrm{cN} 0 \mathrm{pN}+$ group compared with the $\mathrm{cNOpN0}$ group.

However, the findings showed no significant differences in overall survival $(23.3 \%$ vs $26.4 \%$; HR $0.92 ; 95 \%$ CI $0.77-1.09 ; P=0.331)$ or event-free survival $(20.7 \%$ vs 20.4\%; HR 0.84; 95\% CI 0.71-1.00; $P=0.050$ ) between the $\mathrm{cN} 0 \mathrm{pN}+$ and $\mathrm{cN}+\mathrm{pN}+$ groups (Fig. 1). The findings also showed no significant differences between these groups in overall recurrence (64.6\% vs $68.3 \%$; HR 0.83 ; 95\% CI 0.66-1.04; $P=0.104)$, locoregional recurrence 
TABLE 2 Comparison of tumor pathology and postoperative outcomes according to clinical (cN)/pathologic (pN) node groups

\begin{tabular}{|c|c|c|c|c|c|c|}
\hline Variable & $\begin{array}{l}\text { Overall incidence }(n= \\
1554) n(\%)\end{array}$ & $\begin{array}{l}\text { cNOpNO }(n=613) \\
n(\%)\end{array}$ & $\begin{array}{l}\mathrm{cN} 0 \mathrm{pN}+(n=403) \\
n(\%)\end{array}$ & $\begin{array}{l}\mathrm{cN}+\mathrm{pN} 0(n=220) \\
n(\%)\end{array}$ & $\begin{array}{l}\mathrm{cN}+\mathrm{pN}+(n=318) \\
n(\%)\end{array}$ & $P$ value \\
\hline \multicolumn{6}{|l|}{ Histologic subtype } & $<0.001$ \\
\hline $\begin{array}{l}\text { Squamous cell } \\
\text { cancer }\end{array}$ & $719(46.3)$ & $302(49.3)$ & $176(43.7)$ & $122(55.5)$ & $119(37.4)$ & \\
\hline Adenocarcinoma & $835(53.7)$ & $311(50.7)$ & $227(56.3)$ & $98(44.5)$ & $199(62.6)$ & \\
\hline \multicolumn{6}{|l|}{ Tumor differentiation } & $<0.001$ \\
\hline Good & $533(34.3)$ & $237(38.7)$ & $115(28.5)$ & $86(39.1)$ & $95(29.9)$ & \\
\hline Average & $540(34.7)$ & $185(30.2)$ & $175(43.4)$ & $64(29.1)$ & $116(36.5)$ & \\
\hline Poor & $239(15.4)$ & $60(9.8)$ & $72(17.9)$ & $29(13.2)$ & $78(24.5)$ & \\
\hline Data missing & $242(15.6)$ & $131(21.4)$ & $41(10.2)$ & $41(18.6)$ & $29(9.2)$ & \\
\hline \multicolumn{6}{|l|}{ pT category } & $<0.001$ \\
\hline $\mathrm{pT} 0 / 1$ & $631(40.6)$ & $416(67.9)$ & $73(18.1)$ & $108(49.1)$ & $34(10.7)$ & \\
\hline pT2 & $267(17.2)$ & $82(13.4)$ & $89(22.1)$ & $36(16.4)$ & $60(18.9)$ & \\
\hline pT3 & $575(37.0)$ & $102(16.6)$ & $211(52.4)$ & $68(30.9)$ & $194(61.0)$ & \\
\hline pT4 & $81(5.2)$ & $13(2.1)$ & $30(7.4)$ & $8(3.6)$ & $30(9.4)$ & \\
\hline \multicolumn{6}{|l|}{ pN category } & $<0.001$ \\
\hline $\mathrm{pN} 0$ & $833(53.6)$ & $613(100)$ & $0(0)$ & $220(100)$ & $0(0)$ & \\
\hline $\mathrm{pN} 1$ & $352(22.7)$ & $0(0)$ & $212(52.6)$ & $0(0)$ & $140(44.0)$ & \\
\hline $\mathrm{pN} 2$ & $208(13.4)$ & $0(0)$ & $117(29.0)$ & $0(0)$ & $91(28.6)$ & \\
\hline $\mathrm{pN} 3$ & $161(10.4)$ & $0(0)$ & $74(18.4)$ & $0(0)$ & $87(27.4)$ & \\
\hline \multicolumn{6}{|l|}{ pTNM stage } & $<0.001$ \\
\hline 0 & $59(3.8)$ & $47(7.7)$ & $0(0)$ & $12(5.5)$ & $0(0)$ & \\
\hline I & $583(37.5)$ & 451 (73.6) & $0(0)$ & $132(60.0)$ & $0(0)$ & \\
\hline II & $328(21.1)$ & $102(16.6)$ & $108(26.8)$ & $68(30.9)$ & $50(15.7)$ & \\
\hline III & $584(37.6)$ & $13(2.1)$ & $295(73.2)$ & $8(3.6)$ & $268(84.3)$ & \\
\hline \multicolumn{6}{|l|}{ Resection margin } & $<0.001$ \\
\hline R0 & 1377 (88.6) & $576(94.0)$ & $347(86.1)$ & $197(89.5)$ & $257(80.8)$ & \\
\hline $\mathrm{R} 1 / \mathrm{R} 2$ & $177(11.4)$ & $37(6.0)$ & $56(13.9)$ & $23(10.5)$ & $61(19.2)$ & \\
\hline $\begin{array}{l}\text { Lymph nodes } \\
\text { harvested }\end{array}$ & $16(3-72)$ & $13(3-70)$ & $17(3-49)$ & $16(3-48)$ & $20(3-72)$ & $<0.001$ \\
\hline $\begin{array}{l}\text { Positive lymph } \\
\text { nodes }\end{array}$ & $0(0-32)$ & $0(0-0)$ & $2(1-32)$ & $0(0-0)$ & $3(1-32)$ & $<0.001$ \\
\hline $\begin{array}{l}\text { In-hospital } \\
\text { mortality }\end{array}$ & $109(7.0)$ & $45(7.3)$ & $21(5.2)$ & $19(8.6)$ & $24(7.5)$ & 0.371 \\
\hline $\begin{array}{l}\text { In-hospital } \\
\text { morbidity }\end{array}$ & $905(58.2)$ & $364(59.4)$ & $220(54.6)$ & $134(60.9)$ & $187(58.8)$ & 0.359 \\
\hline Reintervention & $245(15.8)$ & $101(16.5)$ & $59(14.6)$ & $41(18.6)$ & $44(13.8)$ & 0.411 \\
\hline $\begin{array}{l}\text { Adjuvant therapy } \\
\text { (any) }\end{array}$ & $267(17.2)$ & $28(4.6)$ & 135 & $13(5.9)$ & $91(28.6)$ & $<0.001$ \\
\hline Chemoradiotherapy & $136(8.8)$ & $14(2.3)$ & $63(15.6)$ & $7(3.2)$ & $52(16.4)$ & $<0.001$ \\
\hline Chemotherapy & $105(6.8)$ & $6(1.0)$ & $66(16.4)$ & $4(1.8)$ & $29(9.1)$ & \\
\hline Radiotherapy & $26(1.7)$ & $8(1.3)$ & $6(1.5)$ & $2(0.9)$ & $10(3.1)$ & \\
\hline
\end{tabular}

pTNM pathologic tumor-node-metastasis

(24.9\% vs $29.0 \%$; HR $0.79 ; \quad 95 \%$ CI $0.53-1.17$; $P=0.235)$, distant recurrence $(28.6 \%$ vs $30.6 \%$; HR 0.84 ; $95 \%$ CI $0.59-1.21 ; P=0.355)$, or mixed recurrence $(20.1 \%$ vs $18.9 \%$; HR $0.97 ; \quad 95 \%$ CI $0.63-1.50$; $P=0.889$ ).

\section{Adjusted Comparison of cNOpN+ and cNOpNO Patients}

After adjustment on the propensity score, $\mathrm{cNO} 0 \mathrm{pN}+$ and cNOpNO did not differ significantly in terms of in-hospital mortality or morbidity. Importantly, the $\mathrm{cNO} \mathrm{pN}+$ group showed an increased incidence of R1/R2 resection margin 
FIG. 1 Unadjusted comparison of 5-year overall survival between four groups: cN0pNO, $\mathrm{cN} 0 \mathrm{pN}+, \mathrm{cN}+\mathrm{pNO}$, and $\mathrm{cN}+\mathrm{pN}+(P<0.001)$

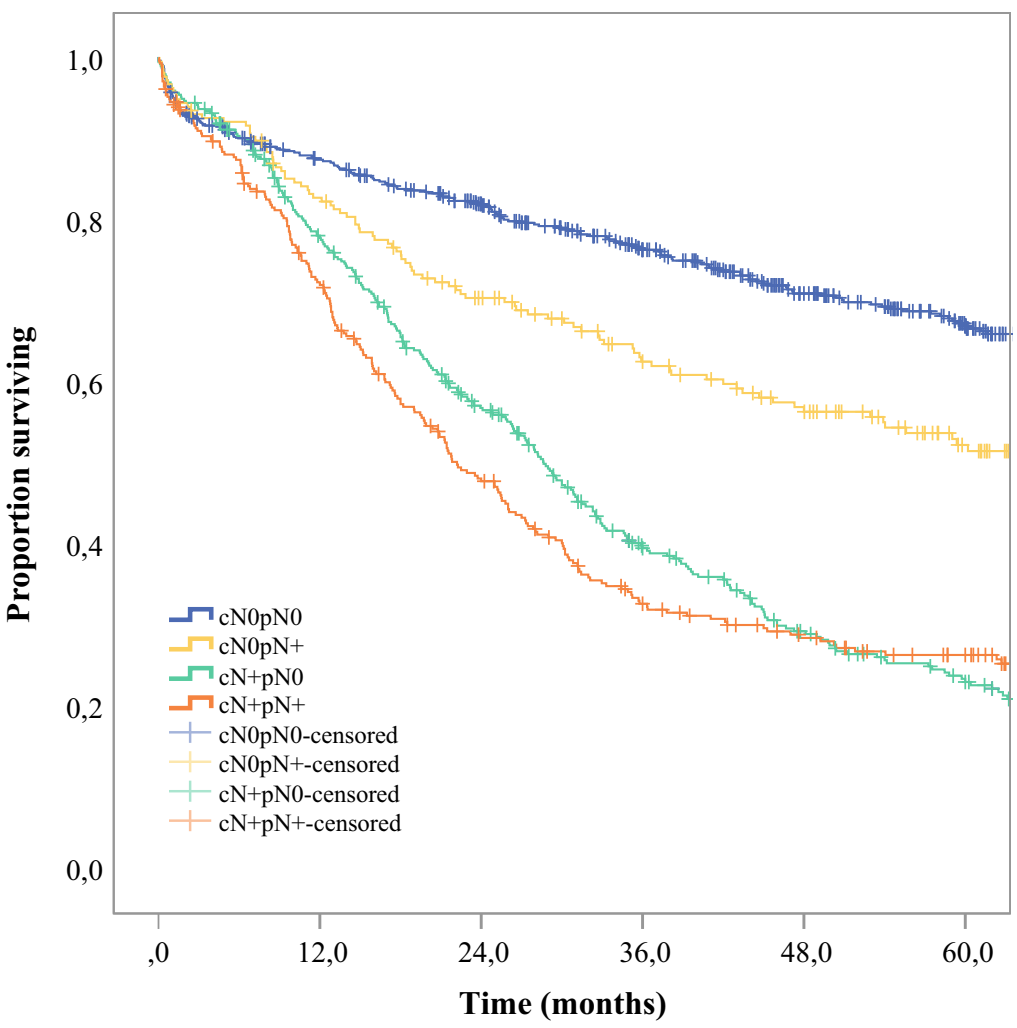

\begin{tabular}{|l|c|c|c|c|c|c|}
\hline cN0pN0 & 613 & 489 & 429 & 352 & 290 & 217 \\
\hline cN0pN+ & 403 & 297 & 204 & 127 & 85 & 61 \\
\hline $\mathbf{c N + p N 0}$ & 220 & 177 & 144 & 116 & 98 & 69 \\
\hline $\mathbf{c N + p N +}$ & 318 & 221 & 143 & 92 & 70 & 55 \\
\hline
\end{tabular}

(OR 1.62; 95\% CI 1.29-2.05; $P<0.001$ ). The 5-year overall survival (HR 3.12; 95\% CI 2.57-3.78; $P<0.001$ ) and event-free survival (HR 2.87; 95\% CI 2.39-3.45; $P<0.001)$ were significantly reduced in the $\mathrm{cN} 0 \mathrm{pN}+$ group. The $\mathrm{cNOpN}+$ group showed significant increases in overall recurrence (HR 4.74; 95\% CI 3.58-6.27; $P<0.001$ ), locoregional recurrence (HR 3.04; 95\% CI 1.97-4.69; $P<0.001$ ), distant recurrence (HR 4.70; 95\% CI 2.86-7.71; $P<0.001$ ), and mixed recurrence (HR 5.60; $95 \%$ CI $3.10-10.12 ; P<0.001)$.

\section{Adjusted Comparison of $c N O p N+$ and $c N+p N+$ Patients}

After adjustment on the propensity score, $\mathrm{cNOpN}+$ and $\mathrm{cN}+\mathrm{pN}+$ did not differ significantly in terms of in-hospital mortality or morbidity, or in terms of R1/R2 resection margins. The groups did not differ significantly in terms of 5-year overall survival (HR 0.94; 95\% CI 0.78-1.12; $P=0.467$ ) or event-free survival (HR $0.87 ; 95 \%$ CI $0.73-1.04 ; P=0.121$ ). The groups also did not differ significantly in terms of overall recurrence (HR 0.88; $95 \%$ CI $0.69-1.11 ; P=0.268$ ), locoregional recurrence (HR $0.83 ; 95 \%$ CI $0.55-1.24 ; P=0.368)$, distant recurrence (HR $0.89 ; 95 \%$ CI $0.61-1.30 ; P=0.549$ ), or mixed recurrence (HR 0.97; 95\% CI 0.62-1.52; $P=0.893$ ).

\section{Adjusted Survival Analyses According to Histologic Subtype and Clinical T Stage (Appendix 1)}

Subset analysis according to the histologic subtype showed that $\mathrm{cNO} 0 \mathrm{pN}+$ had a significantly reduced 5 -year overall survival $(P<0.001)$ and event-free survival $(P<0.001)$ compared with $\mathrm{cNOpNO}$ in both the squamous 
cell and adenocarcinoma subgroups. However, cN0pN+ showed no significant difference in 5-year overall survival $(P>0.108)$ or event-free survival $(P>0.226)$ compared with $\mathrm{cN}+\mathrm{pN}+$ in each histologic subtype.

Subset analysis according to clinical $\mathrm{T}$ stage showed that $\mathrm{cN} 0 \mathrm{pN}+$ had a significantly reduced 5-year overall survival $(P<0.011)$ and event-free survival $(P<0.010)$ compared with cN0pN0 for all clinical T1, T2, T3, and T4 stages. Compared with $\mathrm{cN}+\mathrm{pN}+$ in each clinical $\mathrm{T}$ stage, $\mathrm{cN} 0 \mathrm{pN}+$ showed no significant difference in 5-year overall survival $(P>0.147)$ or event-free survival $(P>0.139)$.

\section{Impact of Adjuvant Treatment in pN+ Groups}

The use of adjuvant therapy was increased in pathologically node-positive groups (Table 1), but without offering any 5 -year survival benefit $(24.0 \%$ vs $26.6 \%$; HR $0.85 ; 95 \%$ CI $0.70-1.03 ; P=0.101)$.

\section{Risk Factors for pN+ Disease for cNO Patients}

Univariable comparison of the $\mathrm{pN}+$ and $\mathrm{pN} 0$ groups demonstrated significant increases in the $\mathrm{pN}+$ group in the proportion of males $(81.9 \%$ vs $79.0 \% ; P=0.018)$, tumors in the lower third $(62.3 \%$ vs $44.7 \%$; $P<0.001)$, malnourished patients $(20.1 \%$ vs $9.0 \% ; P<0.001)$, clinical T3/4 tumors $(59.9 \%$ vs $37.8 \% ; P<0.001)$, adenocarcinoma histologic subtype $(59.1 \%$ vs $49.1 \% ; P<0.001)$, and poor tumor differentiation $(20.8 \%$ vs $10.7 \% ; P<0.001)$. Regression analysis-confirmed variables independently associated with $\mathrm{pN}+$ disease included lower third tumor location (OR 3.11; 95\% CI 2.13-4.54; $P<0.001$ ), advanced clinical $\mathrm{T}$ (T3/T4) stage (OR 7.70; 95\% CI 5.48-10.82; $P<0.001)$, and poor tumor differentiation (OR 2.13; 95\% CI 1.51-3.00; $P<0.001$ ).

\section{DISCUSSION}

The results of this large retrospective multicenter European study suggest that the long-term prognosis for $\mathrm{cN} 0 \mathrm{pN}+$ esophageal cancer patients is significantly worse than for $\mathrm{cN} 0 \mathrm{pN} 0$ patients, but similar to that for $\mathrm{cN}+\mathrm{pN}+$ patients. Adjuvant therapy failed to alter the prognosis in the $\mathrm{cN} 0 \mathrm{pN}+$ group. Variables associated with $\mathrm{pN}+$ disease included lower third tumor location, advanced clinical $\mathrm{T}$ stage, and poor tumor differentiation, suggesting a highrisk cohort of cN0 patients who may benefit from neoadjuvant therapy before surgery.

Important limitations must be considered when the results from this study are interpreted, including its retrospective observational design. To minimize any bias associated with data collection methods during this study, an independent monitoring team audited the data capture to minimize missing data, to control concordance, and to ensure inclusion of consecutive patients. Despite these steps, $22 \%$ of the cases in the propensity-matched analysis required imputing of data, which may have led to the introduction of bias. However, this effect was limited by the use of random assumption and a regression-switching approach to imputation.

Furthermore, despite analysis and control for many important factors that can influence long-term survival and cancer recurrence using propensity score-matched and multivariable analyses, other potential confounding variables exist that were not studied. Preoperative tumoral staging quality could be questioned, but the approach to clinical staging was similar between all the study centers, and as described by the French national guidelines, used a combination of endoscopic ultrasound for tranversable tumors, CT scans, and, on demand, PET. In addition, such a large multicentric study reflects most common clinical practice and probably a high standard when the expertise of the centers is considered.

Some patients with locally advanced tumors were primarily treated by surgery, whereas the current guidelines recommend neoadjuvant chemoradiotherapy. ${ }^{9}$ Even if based on European practices, this may lead to some criticism. However, the same observation has been published very recently based on a French nationwide population. ${ }^{20}$ This may be explained by the 11-year study period, with a high level of evidence for the benefit of neoadjuvant chemoradiotherapy only recently reported and implemented in clinical practice. ${ }^{7}$ This highlights how important it is for a specialized multidisciplinary team meeting in a center with high surgical volume to offer patients the optimal treatment plan at the time of diagnosis.

The risk of local nodal invasion increases with increasing depth of tumor invasion ( $T$ stage) because the lymphatic drainage of the esophagus is predominantly submucosal. Dubecz et al. $^{21}$ showed in a large national series that the risk of nodal invasion in T1a esophageal cancer ranged from 6.4 to $9.5 \%$, which increased to 19.6-22.9\% for T1b tumors. We also showed that the incidence of node-positive disease in patients with clinical T2N0 disease receiving primary surgery was $50 \% .^{22}$ The results of this study also highlight the critical importance of accuracy in establishing advanced clinical $\mathrm{T}$ stage to identify patients at risk for pathologic nodal positive disease and a poor prognosis.

Although all the centers included in the French EsoGastric Tumors (FREGAT) group were experienced esophageal cancer centers, it must be acknowledged that $40 \%$ of the patients staged as clinical No went on to have pathologic $\mathrm{N}+$ at surgery, highlighting the ongoing challenges with accuracy of clinical staging. Furthermore, an unexpected finding was the correlation of lower-third 
tumor location with pathologic nodal positivity, which may be secondary to the challenges of accurate performance and assessment of nodal spread using endoscopic ultrasound for distal esophageal tumors.

The association of poor tumor differentiation with pathologic nodal positivity also was demonstrated. However this raises the additional importance of good clinical staging endoscopy by experienced endoscopists with adequate biopsies to establish tumor differentiation accurately.

The results of this present study suggest that lymph nodes that are positive but remain undetected clinically $(\mathrm{cNOpN}+)$ have the same prognosis as those detected clinically before surgery $(\mathrm{cN}+\mathrm{pN}+)$. This implies that lymph node size allowing radiologic detection is not a prognostic indicator influencing survival.

The current study clearly demonstrated the prognostic importance of nodal positivity, with a 5-year survival rate of approximately $20 \%$ for patients with pathologic nodal positivity who received surgery alone. Similar to previous publications, we demonstrated the lack of survival benefit seen with adjuvant chemotherapy for lymph node-positive patients. ${ }^{23}$ However, neoadjuvant therapy commonly results in downstaging of esophageal cancer and has been shown to improve survival in several randomized controlled trials. ${ }^{4-8}$ Nevertheless, the presence of positive lymph nodes after neoadjuvant therapy has been shown to confer a poor prognosis in terms of long-term survival. ${ }^{24,25}$ Thus, although the results of this study suggest that patients who have clinical N0 disease with risk factors for pathologic positivity should receive neoadjuvant therapy, it must be noted that a portion of these patients will fail to respond. Therefore, an important area of future research remains, namely, identification of responders to neoadjuvant therapy so a patient- and tumor-tailored approach to the management of esophageal cancer can be provided.

Interestingly, the $\mathrm{cN}+\mathrm{pN} 0$ patients had an intermediate prognosis between that of the $\mathrm{cNO} 0 \mathrm{pN} 0$ and $\mathrm{cN}+\mathrm{pN}+$ patients. Because only patients treated with primary surgery were included in the study, the mechanism of this intermediate prognosis remains unclear, but may be a reflection of differences in $\mathrm{pT}$ stage or nodal clearance at surgery. This highlights the fact that even if the prognosis of esophageal cancer is primarily driven by pathologic lymph node invasion, clinical lymph node involvement also has a prognostic role to be taken into account when neoadjuvant treatment is considered, as well as clinical $\mathrm{T}$ stage classification.

\section{CONCLUSION}

This large multicenter retrospective European study showed that $\mathrm{cNOpN}+$ has a prognosis similar to that of $\mathrm{cN}+\mathrm{pN}+$ and substantially worse than that of cNOpNO. Patients with clinical N0 disease but risk factors for pathologic $\mathrm{N}+$ disease, including advanced $\mathrm{T}$ stage, lower third tumor location, and poor tumor differentiation, may benefit from neoadjuvant therapy before surgery.

ACKNOWLEDGEMENTS Sheraz R. Markar is supported by the National Institute for Health Research (NIHR Clinical Trial Fellowship: NIHR-CTF-2015-04-09). The views expressed in this publication are those of the authors and not necessarily those of the NIHR, NHS, or the Department of Health.

DISCLOSURE The authors declare that they have no conflict of interest.

OPEN ACCESS This article is distributed under the terms of the Creative Commons Attribution 4.0 International License (http:// creativecommons.org/licenses/by/4.0/), which permits unrestricted use, distribution, and reproduction in any medium, provided you give appropriate credit to the original author(s) and the source, provide a link to the Creative Commons license, and indicate if changes were made.

\section{APPENDIX 1: ADJUSTED SURVIVAL ANALYSES ACCORDING TO THE HISTOLOGIC SUBTYPE AND CLINICAL T STAGE}

\section{Squamous Cell Carcinoma}

Subset analysis of the squamous cell carcinoma histologic subtype showed that $\mathrm{cNOpN}+$ had a significantly reduced 5-year overall survival (hazard ratio [HR] 2.36; 95\% confidence interval $[\mathrm{CI}] 1.82-3.07 ; P<0.001)$ and event-free survival (HR 2.04; 95\% CI 1.60-2.62; $P<0.001$ ) compared with cNOpNO. However, $\mathrm{cNOpN}+$ showed no significant difference in 5-year overall survival (HR 0.80; 95\% CI 0.61-1.05; $P=0.108$ ) or event-free survival (HR $0.85 ; 95 \%$ CI $0.64-1.11 ; P=0.226$ ) compared with $\mathrm{cN}+\mathrm{pN}+$.

\section{Adenocarcinoma}

Similarly, subset analysis of the adenocarcinoma histologic subtype showed that $\mathrm{cNOpN}+$ had a significantly reduced 5-year overall survival (HR 4.08; 95\% CI 3.05-5.48; $P<0.001$ ) and event-free survival (HR 4.10; 95\% CI 3.08-5.45; $P<0.001)$ compared with cN0pN0. Again, cN0pN+ showed no significant difference in 5-year overall survival (HR 1.06; 95\% CI 0.84-1.34; $P=0.608$ ) or event-free survival (HR 0.91; 95\% CI 0.73-1.14; $P=0.433$ ) compared with $\mathrm{cN}+\mathrm{pN}+$. 


\section{Clinical T1 and T2 Stages}

For clinical T1 stage, cNOpN+ had a significantly reduced 5-year overall survival (HR 3.46; 95\% CI 2.32-5.16; $P<0.001$ ) and event-free survival (HR 3.22; 95\% CI 2.19-4.74; $P<0.001)$ compared with cN0pN0. Compared with $\mathrm{cN}+\mathrm{pN}+, \mathrm{cN} 0 \mathrm{pN}+$ showed no significant difference in 5-year overall survival (HR 1.80; 95\% CI $0.75-4.34 ; P=0.191$ ) or event-free survival (HR 1.87; $95 \%$ CI $0.78-4.50 ; P=0.163$ ).

Subset analysis of clinical T2 stage showed that $\mathrm{cN} 0 \mathrm{pN}+$ had a significantly reduced 5 -year overall survival (HR 3.30; 95\% CI 2.34-4.65; $P<0.001$ ) and eventfree survival (HR 3.08; 95\% CI 2.22-4.27; $P<0.001$ ) compared with cNOpNO. Compared with $\mathrm{cN}+\mathrm{pN}+$, $\mathrm{cN} 0 \mathrm{pN}+$ showed no significant difference in 5-year overall survival (HR 1.09; 95\% CI $0.78-1.53 ; P=0.606$ ) or event-free survival (HR 1.01; 95\% CI $0.73-1.40$; $P=0.951)$.

\section{Clinical T3 and T4 Stage}

Subset analysis of clinical T3 stage showed that $\mathrm{cN} 0 \mathrm{pN}+$ had a significantly reduced 5-year overall survival (HR 1.68; 95\% CI 1.13-2.50; $P=0.011$ ) and eventfree survival (HR 1.66; 95\% CI 1.13-2.44; $P=0.010$ ) compared with cN0pNO. Compared with $\mathrm{cN}+\mathrm{pN}+$, $\mathrm{cN} 0 \mathrm{pN}+$ showed no significant difference in 5-year overall survival (HR $0.81 ; 95 \%$ CI $0.61-1.08 ; P=0.147$ ) or event-free survival (HR $0.81 ; 95 \%$ CI $0.62-1.07$; $P=0.139$ ).

For clinical T4 stage, cNOpN+ had a significantly reduced 5-year overall survival (HR 3.09; 95\% CI 2.02-4.73; $P<0.001$ ) and event-free survival (HR 2.50; 95\% CI 1.68-3.71; $P<0.001)$ compared with cN0pN0. Compared with $\mathrm{cN}+\mathrm{pN}+, \mathrm{cN} 0 \mathrm{pN}+$ showed no significant difference in 5-year overall survival (HR 1.01; 95\% CI $0.69-1.48 ; P=0.953$ ) or event-free survival (HR 0.78; $95 \%$ CI $0.54-1.13 ; P=0.189$ ).

\section{APPENDIX 2: COLLABORATORS LIST}

Department of Digestive Surgery Bordeaux, France: Guillaume Luc, MD. Department of Thoracic Surgery Bordeaux, France: Magalie Cabau, MD; Jacques Jougon MD, PhD. Department of Digestive Surgery, Brest, France: Bogdan Badic, MD; Patrick Lozach, MD, PhD. Department of Digestive Surgery, Brussels ULB Erasme Bordet University, Brussels, Belgium: Issam El Nakadi, MD, PhD; Serge Cappeliez, MD, PhD. Department of Digestive Surgery, Caen, France: Gil Lebreton, MD; Jean Lubrano, MD, $\mathrm{PhD}$; Arnaud Alves, MD, PhD. Department of Digestive
Surgery, Clermont-Ferrand, France: Renaud Flamein, MD; Denis Pezet, MD, PhD. Department of Digestive Surgery, Louis Mourier University Hospital, Paris, France: Federica Pipitone, MD; Bogdan Stan Iuga, MD; Nicolas Contival, MD; Eric Pappalardo, MD. Department of Digestive Surgery, Lausanne University Hospital, Lausanne, Switzerland: Styliani Mantziari, MD; Nicolas Demartines, MD, PhD. Department of Digestive Surgery, Lille, France: Flora Hec, MD; Marguerite Vanderbeken, MD; Sébastien Degisors, MD; Hélène Marin, MD. Department of Digestive Surgery, Limoges, France: Fabien Fredon, MD; Alain Gainant, MD; Muriel Mathonnet, MD, PhD. Department of Digestive Surgery, Croix Rousse University Hospital, Lyon, France: Jean-Marc Bigourdan, MD; Salim Mezoughi, MD; JeanYves Mabrut, MD, PhD; Christian Ducerf, MD. Department of Digestive Surgery, Edouard Herriot University Hospital, Lyon, France: Oussama Baraket, MD; Gilles Poncet, MD. Department of Digestive Surgery, Lyon Sud University Hospital, Lyon, France: Delphine Vaudoyer, MD; Peggy Jourdan Enfer, MD; Laurent Villeneuve, MD; Olivier Glehen, MD, PhD. Department of Digestive Surgery, Montpellier, France: Thibault Coste, MD; Jean Michel Fabre, MD, PhD. Department of Digestive Surgery, Institut de Cancérologie de Lorraine, Nancy, France: Frédéric Marchal, MD. Department of Digestive Surgery, Nancy, France: Romain Frisoni, MD; Ahmet Ayav, MD, PhD; Laurent Brunaud, MD, PhD; Laurent Bresler, MD, PhD. Department of Thoracic Surgery, Nice, France: Charlotte Cohen, MD; Olivier Aze, MD; Nicolas Venissac, MD; Daniel Pop, MD; Jérôme Mouroux, MD. Department of Digestive Surgery, Nîmes, France: Ion Donici, MD; Michel Prudhomme, MD, PhD. Department of Digestive Surgery, Pitié Salpétrière University Hospital, Paris, France: Emanuele Felli, MD; Stéphanie Lisunfui, MD; Marie Seman, MD; Gaelle Godiris Petit, MD; Mehdi Karoui, MD, PhD; Christophe Tresallet, MD, PhD; Fabrice Ménégaux, MD, $\mathrm{PhD}$. Department of Digestive Surgery, Lariboisière University Hospital, Paris, France: Brice Malgras, MD; Denis Lantuas, MD; Karine Pautrat, MD; Marc Pocard, MD, $\mathrm{PhD}$.

\section{REFERENCES}

1. Mariette C, Piessen G, Briez N, et al. Oesophago-gastric junction adenocarcinoma: which therapeutic approach? Lancet Oncol. 2011;12:296-305.

2. Markar SR, Bodnar A, Rosales J, et al. The impact of neoadjuvant chemoradiotherapy on perioperative outcomes, tumor pathology, and survival in clinical stage II and III esophageal cancer. Ann Surg Oncol. 2013;20:3935-41.

3. Shapiro J, van Lanschot JJ, Hulshof MC, et al. Effect of neoadjuvant chemoradiotherapy for early-stage esophageal cancer. J Clin Oncol. 2015;33:288-9.

4. Mariette C, Dahan L, Mornex F, et al. Surgery alone versus chemoradiotherapy followed by surgery for stage I and II 
esophageal cancer: final analysis of randomized controlled phase III trial FFCD9901. J Clin Oncol. 2014;32:2416-22.

5. Sjoquist KM, Burmeister BH, Smithers BM, et al. Survival after neoadjuvant chemotherapy or chemoradiotherapy for resectable oesophageal carcinoma: an updated meta-analysis. Lancet Oncol. 2011;12:681-92.

6. Shapiro J, van Lanschot JJ, Hulshof MC, et al. Neoadjuvant chemoradiotherapy plus surgery versus surgery alone for oesophageal or junctional cancer (CROSS): long-term results of a randomised controlled trial. Lancet Oncol. 2015;16:1090-8.

7. Van Hagen P, Hulshof MC, van Lanschot JJ, et al. Preoperative chemoradiotherapy for esophageal or junctional cancer. $N$ Engl $J$ Med. 2012;366:2074-84.

8. Klevebro F, von Dobeln GA, Wang N, et al. A randomized clinical trial of neoadjuvant chemotherapy versus neoadjuvant chemoradiotherapy for cancer of the oesophagus or gastro-oesophageal junction. Ann Oncol. 2016;27:660-7.

9. Lordick F, Mariette C, Haustermans K, Obermannova R, Arnold D. Oesophageal cancer: ESMO clinical practice guidelines for diagnosis, treatment and follow-up. Ann Oncol. 2016;27(Suppl 5):50-7.

10. Horgan AM, Darling G, Wong R, et al. Adjuvant sunitib following chemoradiotherapy and surgery for locally advanced esophageal cancer: a phase II trial. Dis Esophagus. 2016;29:1152-8.

11. Stiles BM, Mirza F, Coppolino A, et al. Clinical T2-T2NOMO esophageal cancer: the risk of node positive disease. Ann Thorac Surg. 2011;92:491-6.

12. Rice TW, Mason DP, Murthy SC, et al. T2N0M0 esophageal cancer. J Thorac Cardiovasc Surg. 2007;133:317-24.

13. Markar S, Gronnier C, Duhamel A, et al. Pattern of postoperative mortality after esophageal cancer resection according to center volume: results from a large European multicenter study. Ann Surg Oncol. 2015;22:2615-23.

14. Societe National Francaise de Gastro-Enterologie. Cancer de L'Oesophage. 1 March 2013. http://www.tncd.org/. Accessed 27 April 2017.
15. Briez N, Piessen G, Bonnetain F, et al. Open versus laparoscopically assisted oesophagectomy for cancer: a multicenter randomised controlled phase III trial-the MIRO trial. BMC. 2011;11:310.

16. Sobin LH, Gospodarowicz MK, Wittekind Ch. TNM classification of malignant tumours. 7th ed. Wiley, Hoboken 2009.

17. Mattei A. Estimating and using propensity score in presence of missing background data: an application to assess the impact of childbearing on well-being. Stat Methods Appl. 2009;18:257-73.

18. Van Buuren S, Groothuis-Oudshoorn K. MICE: multivariate imputation by chained equations in R. J Stat Softw. 2011.

19. Rubin DB. Multiple Imputation for Nonresponse in Surveys. Wiley, Hoboken 1987.

20. Pasquer A, Renaud F, Hec F, et al. Is centralization needed for esophageal and gastric cancer patients with low operative risk? A nationwide study. Ann Surg. 2016;264:823-30.

21. Dubecz A, Kern M, Solymosi N, et al. Predictors of lymph node metastasis in surgically resected $\mathrm{T} 1$ esophageal cancer. Ann Thorac Surg. 2015;99:1879-85.

22. Markar SR, Gronnier C, Pasquer A, et al. Role of neoadjuvant treatment in clinical T2N0M0 oesophageal cancer: results from a retrospective multi-center European study. Eur $J$ Cancer. 2016;56:59-68.

23. Pasquer A, Gronnier C, Renaud F, et al. Impact of adjuvant chemotherapy on patients with lymph node-positive esophageal cancer who are primarily treated with surgery. Ann Surg Oncol. 2015;22:1340-9.

24. Blackham AU, Yue B, Almhanna K, et al. The prognostic value of residual nodal disease following neoadjuvant chemoradiation for esophageal cancer in patients with complete primary tumor response. J Surg Oncol. 2015;112:597-602.

25. Davies AR, Gossage JA, Zylstra J, et al. Tumor stage after neoadjuvant chemotherapy determines survival after surgery for adenocarcinoma of the esophagus and esophagogastric junction. J Clin Oncol. 2014;32:2983-90. 